\title{
CFD Simulation for Flow over Passenger Car Using Tail Plates for Aerodynamic Drag Reduction
}

\author{
R. B. Sharma ${ }^{1}$, Ram Bansal ${ }^{2}$ \\ ${ }^{1}$ HOD, Mechanical Engineering Department, RJIT BSF ACEDEMY Tekanpur \\ ${ }^{2}$ Research Scholar, Department of Automobile Engineering, RJIT BSF ACEDEMY Tekanpur
}

\begin{abstract}
This work proposes an effective numerical model based on the Computational Fluid Dynamics (CFD) approach to obtain the flow structure around a passenger car with Tail Plates. The experimental work of the test vehicle and grid system is constructed by ANSYS-14.0. FLUENT which is the CFD solver \& employed in the present work. In this study, numerical iterations are completed, then after aerodynamic data and detailed complicated flow structure are visualized.

In the present work, model of generic passenger car has been developed in solid works-10 and generated the wind tunnel and applied the boundary conditions in ANSYS workbench 14.0 platform then after testing and simulation has been performed for the evaluation of drag coefficient for passenger car. In another case, the aerodynamics of the most suitable design of tail plate is introduced and analysedfor the evaluation of drag coefficient for passenger car. The addition of tail plates results in a reduction of the drag-coefficient $3.87 \%$ and lift coefficient $16.62 \%$ in head-on wind. Rounding the edges partially reduces drag in head-on wind but does not bring about the significant improvements in the aerodynamic efficiency of the passenger car with tail plates, it can be obtained. Hence, the drag force can be reduced by using add on devices on vehicle and fuel economy, stability of a passenger car can be improved.
\end{abstract}

Keywords: Aerodynamic Drag, Coefficient of Drag, Coefficient of Lift,Tail Plate, Wind tunnel simulation, ANSYS FLUENT, Generic passenger car, CFD.

\section{Introduction}

A few years ago when fuel crisis was not a problem, cars were mainly designed for high-speed manoeuver, comfort, and safety. However, with the recent impact due to the increasing fuel price since 2002, the sale of automobile industry all over the world crippled. This was immediately followed by many questions raised regarding the effect of oil supply shortage on the future of this industry. Many solutions were certainly suggested and many once-considered-infeasible solutions were now given serious second thoughts. Beside the development of electronic car and fuel cell, other proposed approaches include the integration of air conditioning system with electronic devices to cut down energy consumption, the redesign of car frame and body to reduce its total weight, and the modification of car external to improve the car overall aerodynamic characteristics for better cruising conditions, greater stability of navigation, and lower energy consumption. These subjects are also indirectly related to environmental protection and noise pollution.

In the process of car design, the aerodynamics must be seriously considered. A car design can only be acceptable if its form drag reduced. Many researchers have made use of CFD techniques [1-4] to perform numerical simulations related to automobile.

The current study presents the development process of aerodynamic holography in the vehicle outerbody.Several numerical simulations were performed to analyse the pressure field, velocity vector field, and aerodynamic force prediction related to a passenger car.Then, the stability of the aerodynamic forces caused by the airflow outside the car was identified. After that, the installation of tail plates that leads to lower wind drag is carefully evaluated.Through Fluent $[5,6]$, this work used k-esteady model to compute the flow properties around the car and its tail plates.

As a matter fact, it is very uncommon to use k-e steady model in an iterations-dependent problem. However, it is the goal of this work to demonstrate the feasibility of integrating this very uncommon approach (i.e., the using of k-e steady model) with the computational procedure.Within a relatively short amount of time, this computational process is capable of estimating the aerodynamics of a car at high accuracy.This will provide the automobile research and development teams an alternative approach when performing CAE analysis.

In general, the design criteria of tail plate are only limited to considering the aerodynamics aspect due to the tail plates.Car drivers usually install tail plates that successfully reduce the drag and improve traction leading to better manoeuvre.However, the aero-dynamics performance corresponding to the tail plates has deteriorated severely. For this reason, this work has introduced the designers of tail plate a new direction, tool, and idea for tail plate design process. In the following sections, the methodology will be presented in detail. 


\section{Methodology\& Various Steps}

In this work, first of all a generic model of the passenger car is prepared in the SOLIDWORKS software and this generic model is import into the ANSYS FLUENT to do the simulation of the coefficient of drag and coefficient of lift in the wind tunnel which is generated in the design module of the ANSYS FLUENT. After this the meshing is generated on the surface of the passenger car.

Aerodynamic evaluation of air flow over an object can be performed using analytical method or CFD approach. On one hand, analytical method of solving air flow over an object can be done only for simple flows over simple geometries like laminar flow over a flat plate. If air flow gets complex as in flows over a bluff body, the flow becomes turbulent and it is impossible to solve Navier- Stokes and continuity equations analytically. On the other hand, obtaining direct numerical solution of Navier-stoke equation is not yet possible even with modern day computers. In order to come up with reasonable solution, a time averaged Navier-Stokes equation is being used (Reynolds Averaged Navier-Stokes Equations - RANS equations) together with turbulent models to resolve the issue involving Reynolds Stress resulting from the time averaging process.

In present work the k-e turbulence model with non-equilibrium wall function is selected to analyze the flow over the generic passenger car model. This k-e turbulence model is very robust, having reasonable computational turnaround time, and widely used by the auto industry.

Steps of Analysis

- Select the models of vehicle upon which add on devices are to be used.

- Formation of Base Line Model: Designing of model in solid works with proper dimensions \& parameters.

- Baseline passenger car CFD method and setup: Apply the boundary conditions.

- Generate the wind tunnel for simulation.

- Simulation \& Testing of base line passenger car for drag coefficient and lift coefficient.

- Simulation \& Testing of passenger car with tail plates for drag coefficient \& lift coefficient.

- Impact of add on device on fuel economy of Passenger car.

\section{Formation of Base Line Model}

The base line model of generic passenger car is designed in Solid Works. Figure 1 show the generic passenger car used in the present CFD simulation. The full size generic passenger car is $3395 \mathrm{~mm}$ long, $1490 \mathrm{~mm}$ wide, $1475 \mathrm{~mm}$ high.Then after, this model has been analysed for drag coefficient and forces under the ANSYS14.0 (FULENT) module and values of drag coefficient, lift coefficient

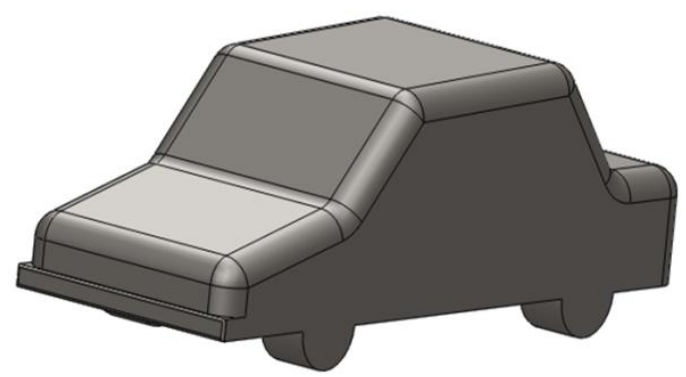

Figure 1 solid-work model of car without VGs

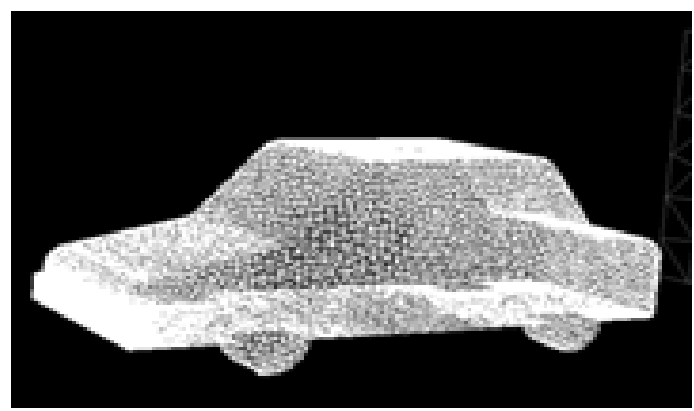

Figure 2 Meshed model of Base Car

The surface mesh of generic passenger car is shown in figure 2. This surface mesh is Tetrahedrons type is generated on its surface.A surface mesh of $1.5 \mathrm{~mm}$ size is created on the vehicle surface. 


\section{Baseline passenger car CFD Simulation and setup}

The CFD simulation by Yang [12] is reproduced in the present simulation. Table 1, Table2, Table 3 and Table 4 shows the solver setup, viscous model and Turbulence model settings, boundary condition settings and solution controls for present simulation respectively.The assumptions made in present simulation have the air flow is steady state with constant velocity at inlet and with zero degree yaw angle, constant pressure outlet, no slip wall boundary conditions at the vehicle surfaces, and inviscid flow wall boundary condition on the top, sidewalls and ground face of the virtual wind tunnel.

Table 1 Solver setting

\begin{tabular}{|l|l|}
\hline $\begin{array}{l}\text { CFD } \\
\text { Simulation }\end{array}$ & $\begin{array}{l}\text { dd dp } \\
\text { Precision })\end{array}$ \\
\hline Solver & \\
\hline Solver & Fluent \\
\hline Space & 3D \\
\hline Formulation & Implicit \\
\hline Time & Steady \\
\hline $\begin{array}{l}\text { Velocity } \\
\text { Formulation }\end{array}$ & Absolute \\
\hline $\begin{array}{l}\text { Gradient } \\
\text { Option }\end{array}$ & Cell-Based \\
\hline $\begin{array}{l}\text { Porous } \\
\text { Formulation }\end{array}$ & Superficial Velocity \\
\hline
\end{tabular}

Table 2 viscous model and Turbulence model settings

\begin{tabular}{|l|l|}
\hline Turbulence Model & k-e (2 eqn) \\
\hline k-epsilon Model & Standard \\
\hline Near-Wall Treatment & $\begin{array}{l}\text { Enhanced } \\
\text { Function }\end{array}$ \\
\hline Operating Conditions & Ambient \\
\hline
\end{tabular}

Table 3 Boundary condition settings

\begin{tabular}{|c|c|c|}
\hline \multicolumn{3}{|c|}{ Boundary Cor } \\
\hline \multirow[t]{4}{*}{ Velocity Inlet } & $\begin{array}{l}\text { Magnitude (Measured } \\
\text { normal to Boundary) }\end{array}$ & $22 \mathrm{~m} / \mathrm{s}$ (constant) \\
\hline & $\begin{array}{l}\text { Turbulence } \\
\text { Method }\end{array}$ & Intensity and Viscosity Ratio \\
\hline & Turbulence Intensity & $1.00 \%$ \\
\hline & Turbulence Viscosity Ratio & 20 \\
\hline \multirow[t]{5}{*}{ Pressure Outlet } & Gauge Pressure magnitude & 0 pascal \\
\hline & Gauge Pressure direction & normal to boundary \\
\hline & $\begin{array}{l}\text { Turbulence } \\
\text { Method }\end{array}$ & Intensity and Viscosity Ratio \\
\hline & $\begin{array}{ll}\text { Backflow } & \text { Turbulence } \\
\text { Intensity } & \\
\end{array}$ & $10 \%$ \\
\hline & $\begin{array}{ll}\text { Backflow } & \text { Turbulent } \\
\text { Viscosity Ratio } & \\
\end{array}$ & 10 \\
\hline Wall Zones & \multicolumn{2}{|l|}{$\begin{array}{l}\text { - vehicle surface-noslip wall B/c } \\
\text { - Ground face- invicisd wall B/C } \\
\text {-Side faces -inviscid wall B/C }\end{array}$} \\
\hline Fluid Properties & Fluid Type & Air \\
\hline & Density & $\rho=1.175\left(\mathrm{~kg} / \mathrm{m}^{\wedge} 3\right)$ \\
\hline & Kinematic viscosity & $\mathrm{v}=1.7894 \times 10^{\wedge}(-5)(\mathrm{kg}(\mathrm{m} \cdot \mathrm{s}))$ \\
\hline
\end{tabular}


Table 4 Solution Controls

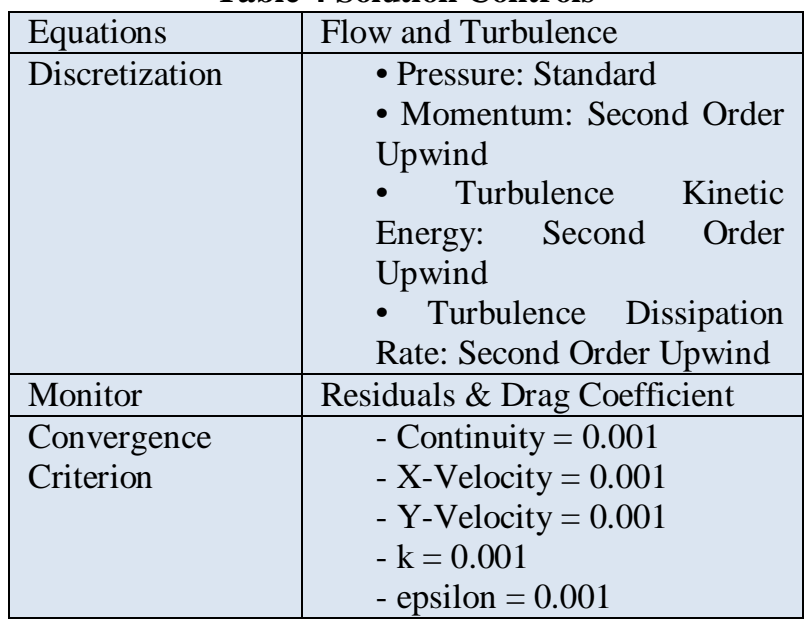

\section{Simulation and testing of Baseline passenger car for drag coefficient \& lift coefficient}

Figure 7 shows the pressure coefficient plot on the car surface for base model simulation. The pressure coefficient plot shows that the stagnation point is created on the front surface of the passenger car. The pressure coefficient also indicates that CFD simulations have a tendency to overshoot the $C_{P}$ value at stagnation point. The Maximum $\mathrm{C}_{\mathrm{P}}$ value obtained in base model simulation is $\mathrm{C}_{\mathrm{P}}=2.0$.

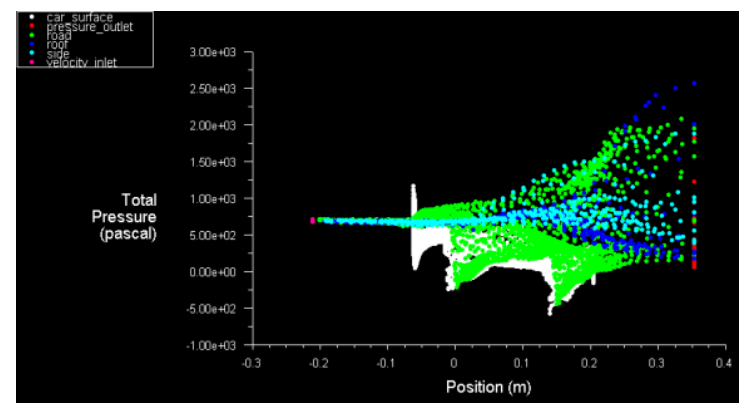

Figure 3 Total Pressure on car surface, Velocity inlet, pressure outlet and road of base model

Figure 4 and 5 are shows the Coefficients of drag $\left(C_{D}\right)$ and Coefficients of lift $\left(C_{L}\right)$ on the base model. Maximum value of the coefficient of drag is 0.3512 and the Maximum value of the coefficient of lift is 0.2310 .

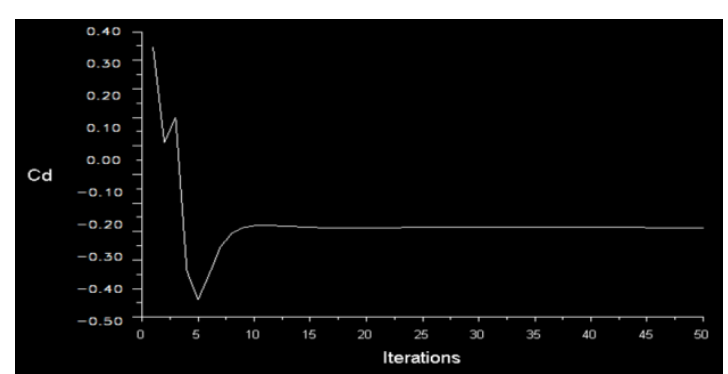

Figure 4 Drag Coefficients $C_{D}$ of base model

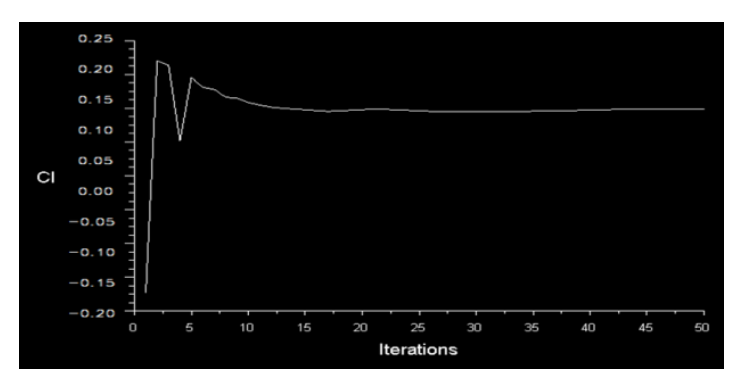

Figure 5 Lift Coefficients $C_{L}$ of base model 


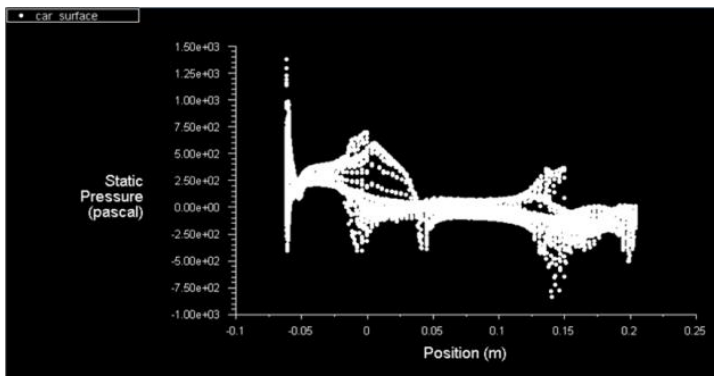

Figure 6 Static pressure distributionon Base model car surface

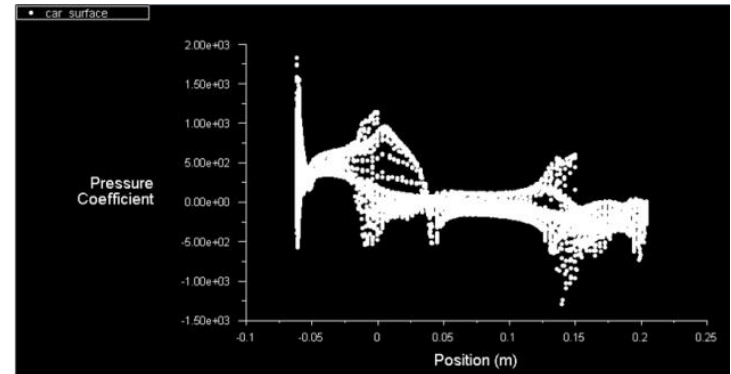

Figure 7 Pressure Coefficient on Base model Car surface

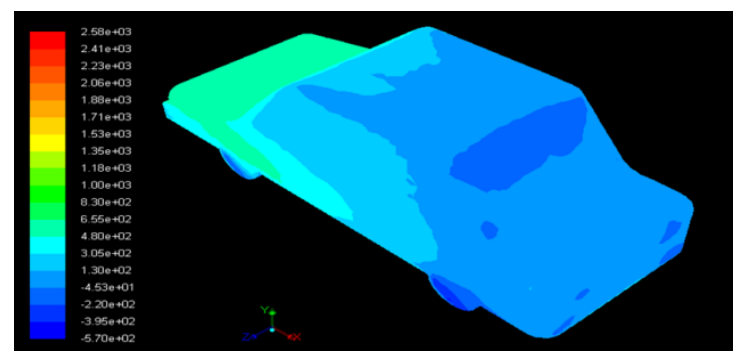

Figure 8 Total pressure on surface of the of base model passenger car

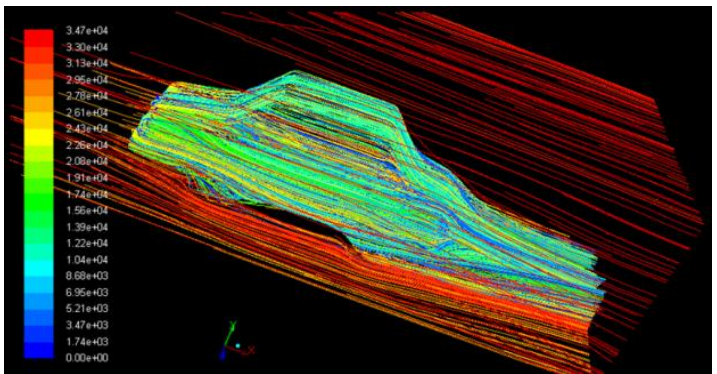

Figure 9 Path lines on surface of the of base model passenger car

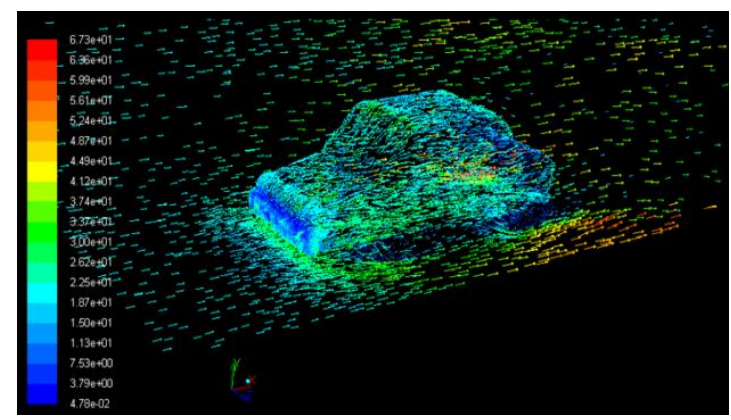

Figure 10 Velocity Vector on surface of the of base model passenger car 


\section{Simulation and testing of passenger car with Tail Plates for drag coefficient \& lift coefficient}

First, a background on vehicle aerodynamics will be covered, including explanation of the concepts. Next, the procedure for building a basic model, including the passenger car and wind tunnel, along with dimensions and simulation parameters, will be developed. The basic model will then be compared with a reputable benchmark to confirm validity of the simulation setup and corresponding results. Once the basic simulation model is benchmarked, it will then be modified to include the external drag reduction devices.

The Tail plates are placed at back side of the roof and at the tail bumper of the passenger car at $12^{\circ}$ inclination angle. The arrangement of them is shows in the figure 11.

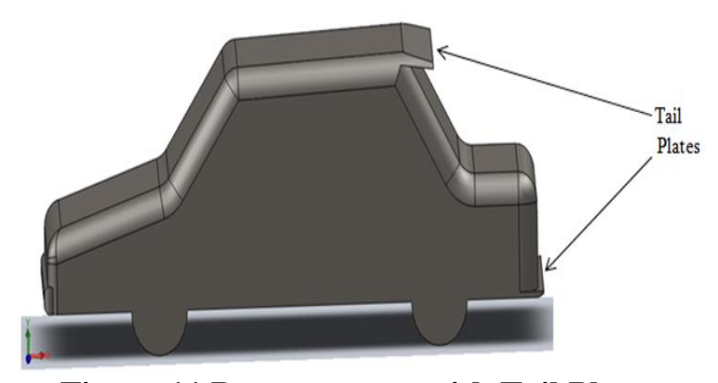

Figure 11 Passenger car with Tail Plates

Figure 12 is shows the Mesh generated on the surface of the model of Generic Passenger car with Tail Plates. The tetrahedron mesh is generated on its surface and a surface mesh of $1.5 \mathrm{~mm}$ size is created on the vehicle surface.

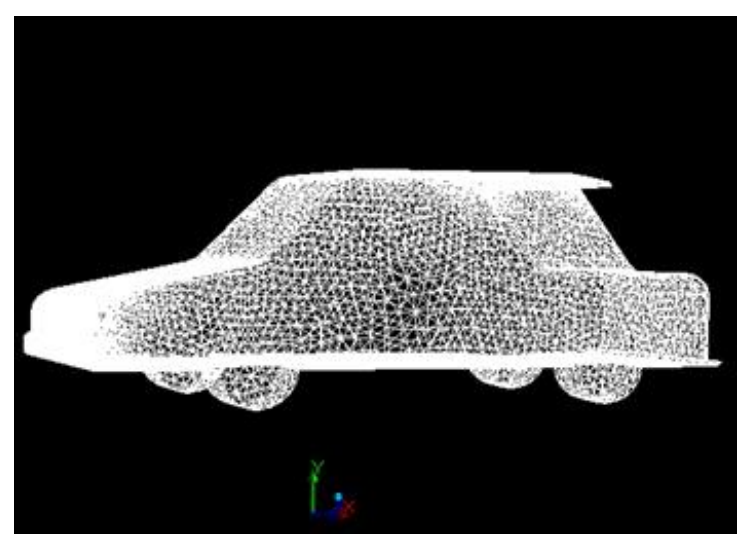

Figure 12 Meshed model of the Passenger car with Tail Plates

Figure 13 is shows the total pressure distribution on the car surface, velocity inlet, pressure outlet, side wall and on the road. The distribution of pressure on the front bumper is $2.250 \mathrm{e}+03$ pascal and at the rear boot is $2.50 \mathrm{e}+02$ pascal are shown in it.

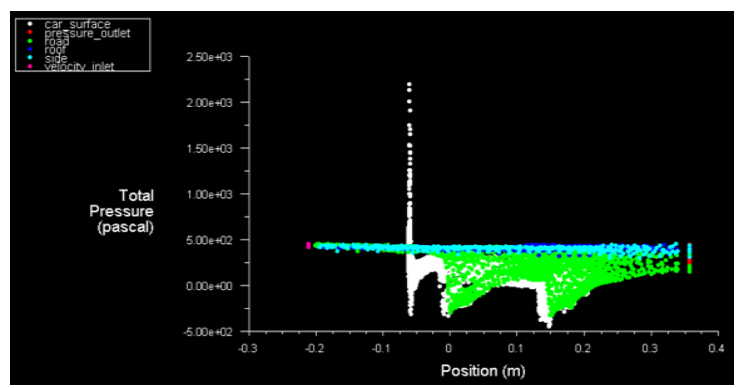

Figure 13 Total Pressure distributions on the car surface, velocity inlet, pressure outlet and on road

The coefficient of drag and coefficient of lift are shown in figure 14 and figure 15 respectively. The maximum value of the Coefficient of drag $\left(C_{D}\right)$ is 0.3376 and the Maximum value of the coefficient of lift $\left(C_{L}\right)$ is 0.1926 . 


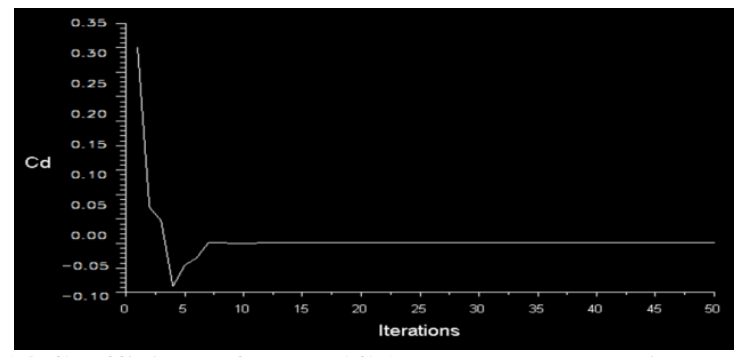

Figure 14 Coefficient of Drag $\left(C_{D}\right)$ passenger car with Tail Plates

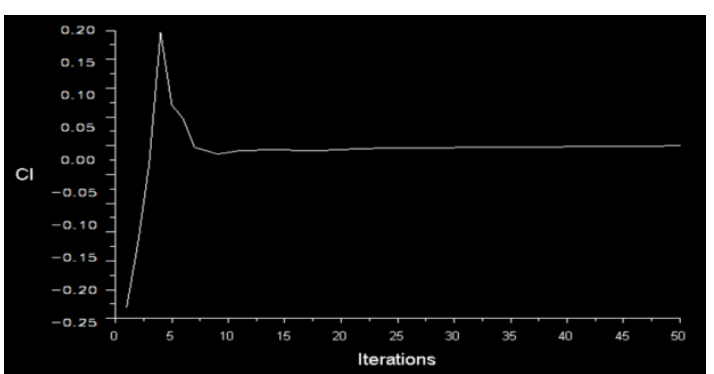

Figure 15 Coefficient of Lift $\left(C_{L}\right)$ passenger car with Tail Plates

The figure 16 shows the distribution of the pressure coefficient on the passenger car surface with tail plates. The value of pressure coefficient on the front bumper is $3.00 \mathrm{e}+03$ and at the rear boot the value of the pressure coefficient is $0.500 \mathrm{e}+02$.

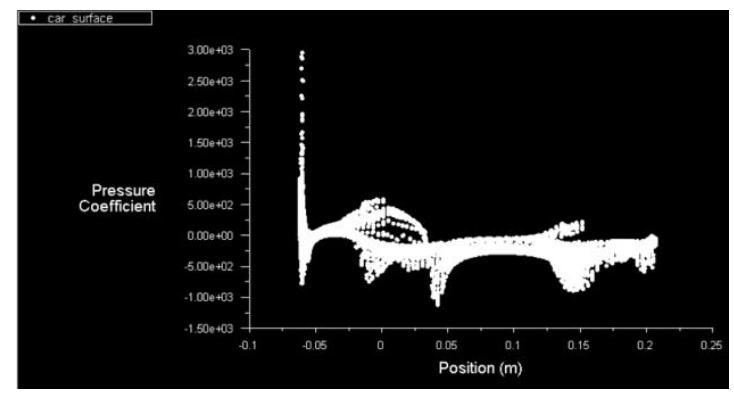

Figure 16 Pressure Coefficient distributions on surface of the car with Tail Plates

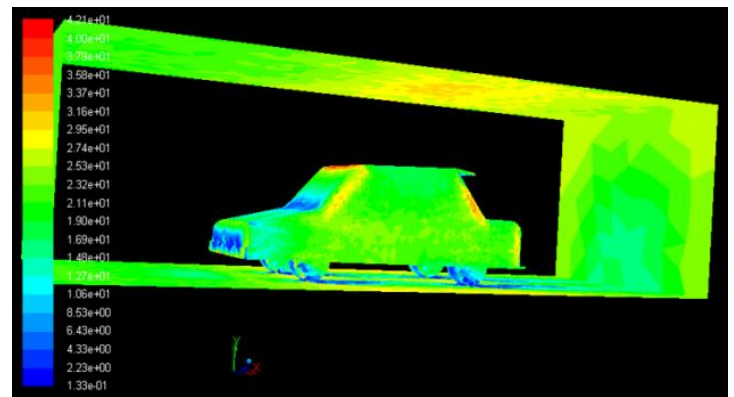

Figure 17Total Pressure Contour on surface of car with Tail Plates

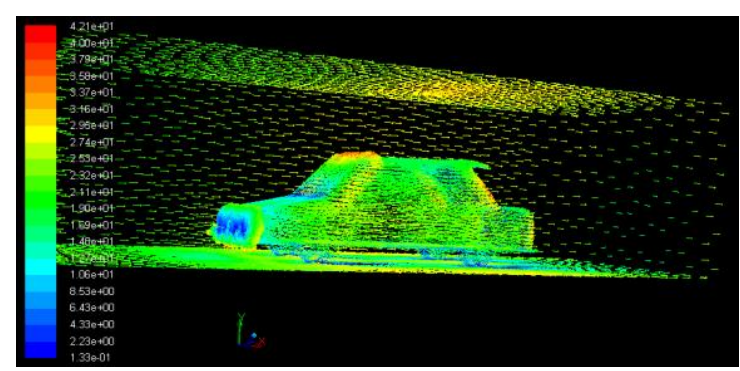

Figure 18 Velocity Vector on surface of car with Tail Plates 


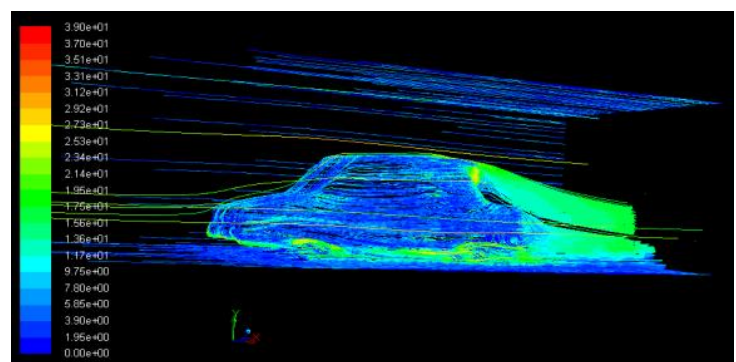

Figure 19 Total Pressure Path Lines on surface of car with Tail Plates

VII. Result

In the case of tail plates are applied on the rear bumper and rear side of roof of the base line car respectively with inclination angle $12^{\circ}$. The coefficient of drag is 0.3376 and the coefficient of lift is 0.1926 . The percentage reduction in drag coefficient in comparison of base line car is $3.87 \%$ and in coefficient of lift is $16.62 \%$. Hence drag force \& lift force on the passenger car is reduced as proportional to drag coefficient and lift coefficient respectively. The comparative results between the baseline car and car with spoiler are shown in table below:

Table 5 Comparison of drag and lift coefficient of baseline Passenger car with a model attached with Pail Plates

\begin{tabular}{|l|l|l|l|l|}
\hline Configurations & $\begin{array}{l}\text { Drag } \\
\text { Coefficient }\end{array}$ & $\begin{array}{l}\% \mathrm{C}_{\mathrm{D}} \\
\text { reduction } \\
\text { from } \\
\text { baseline }\end{array}$ & $\begin{array}{l}\text { Lift } \\
\text { Coefficient }\end{array}$ & $\begin{array}{l}\% \mathrm{C}_{\mathrm{L}} \\
\text { reduction } \\
\text { from } \\
\text { Baseline }\end{array}$ \\
\hline Baseline & 0.351 & 0 & 0.231 & 0 \\
\hline Tail Plates & 0.337 & 3.87 & 0.192 & 16.6 \\
\hline
\end{tabular}

VIII. Conclusion

Computational fluid dynamics (CFD) simulations of the steady flow field around passenger car models with and without Tail Plates were presented and compared the simulated data to each other. The ANSYS-14.0 Fluent with the k-e steady model is used for the simulations of aerodynamics. In this analysis, the coefficient of drag has been reduced $3.87 \%$ and coefficient of lift is reduced $16.62 \%$. Hence, the Tail Plates is the effective tool to reduce the drag force on vehicle.

The effects of different aerodynamic add-on devices on flow and its structure over a generic passenger car may be analysed using CFD approach. The objective is to reduce aerodynamic drag acting on the vehicle and thus improve the fuel efficiency of passenger car. Hence, the drag force can be reduced by using add on devices on vehicle and fuel economy, stability of a passenger car can be improved.

\section{References}

[1] Gilhaus, R. Hoffmann, Directional Stability, Aerodynamics of Road Vehicles, in: W.H. Hucho (Ed.), SAE International, Warrendale, PA, 1998.

[2] J.R. Callister, A.R. George, Wind Noise, Aerodynamics of Road Vehicles, in: W.H. Hucho (Ed.), SAE International, Warrendale, PA, 1998.

[3] F.R. Bailey, H.D. Simon, Future Directions in Computing and CFD, AIAA Paper 92-2734, 1992.

[4] H. Taeyoung, V. Sumantran, C. Harris, T. Kuzmanov, M. Huebler, T. Zak, Flow-field simulations of three simplified vehicle shapes and comparisons with experimental measurements, SAE Transactions 106 (1996) 820-835.

[5] Fluent 6.1 User's Guide, Fluent Inc., Lebanon, NH, 2003.

[6] TGrid 3.4 User's Guide, Fluent Inc., Lebanon, NH, 2001.

[7] B. Lokhande, S. Sovani, J. Xu, Computational Aero-acoustic Analysis of a Generic Side View Mirror, SAE 2003-01-1698, 2003.

[8] Ahmad, K., Khare, M., Chaudhry, K.K., 2002. Model vehicle movement system in wind tunnels for exhaust dispersion studies under various urban street configurations. Journal of Wind Engineering and Industrial Aerodynamics 90, 1051 e 1064.

[9] Abdul Ghani, S.A.A., Aroussi, A., Rice, E., 2001.Simulation of road vehicle natural environment in a climatic wind tunnel. Simulation Practice and Theory 8, 359-375.

[10] Muyl, F., Dumas, L., Herbert, V., 2004. Hybrid method for aerodynamic shape optimization in automotive industry. Computers and Fluids 33, 849-858.

[11] Hucho, Wolf-Heinrich., Sovran, Gino.”Aerodynamics of Road Vehicles” Annual. Reviews Inc. Fluid Mech. 1993.25 :485-537.

[12] Yang, Z., and Khalighi, B., "CFD Simulation for Flow Over Pickup Trucks", SAE Paper No. 2005-01-0547, 2005. 